\title{
Study links sickness to Russian launch site
}

\section{Jim Giles, London}

Rocket launches in Kazakhstan are causing serious illness among people who live near the take-off site, according to an unpublished study seen by Nature.

The Baikonur Cosmodrome is the launch pad for many missions to the International Space Station. But highly toxic fuel from spent rocket stages falls on to the sparsely populated regions close to cosmodrome, where it causes serious health problems, say researchers from Vector, the State Research Center of Virology and Biotechnology in Novosibirsk. The level of some diseases, such as endocrine and blood disorders, in polluted areas is more than twice the regional average, they say.

Epidemiologists outside Russia who have seen the study say that the findings are difficult to verify without more detailed knowledge of how the data were collected. They say that although such results should be regarded with caution, given the sometimes disorganized state of the country's medical records, the problem deserves international attention. Baikonur is run by Rosaviakosmos, the Russian space agency, but both NASA and the European Space Agency (ESA) pay to have craft launched from there.

The most detailed part of the study, led by Vector epidemiologist Sergey Zykov, focuses on children in the Altai Republic, a mountainous region on the southern fringes of Siberia. Zykov chose the republic because it has been contaminated by fuel, such as dimethylhydrazine, that is used to power the early stages of some Russian launchers.

He estimates that a typical launch results in dozens of litres of unburned fuel being sprayed over several square kilometres of land. "These propellants are nasty, toxic substances," says Fabio Caramelli, an engineer at the European Space Research and Technology Centre in Noordwijk, the Netherlands. "A tablespoon of hydrazine in a swimming pool would kill anyone who drank the water."

\section{Health scare}

Zykov examined health records of about 1,000 children in two polluted areas for 1998-2000, comparing them with 330 records from a nearby unpolluted control area. Grouping all cases of disease together, Zykov's team concluded that children from the worst affected area were up to twice as likely to require medical attention during the three years studied and needed to be treated for twice as long.

Local environmental groups have campaigned against the pollution, but this has had little international impact. Zykov says his work is the first to collect the detailed medical statistics needed to confirm that the problem is real. He and his colleagues are now seeking funding for a larger study.

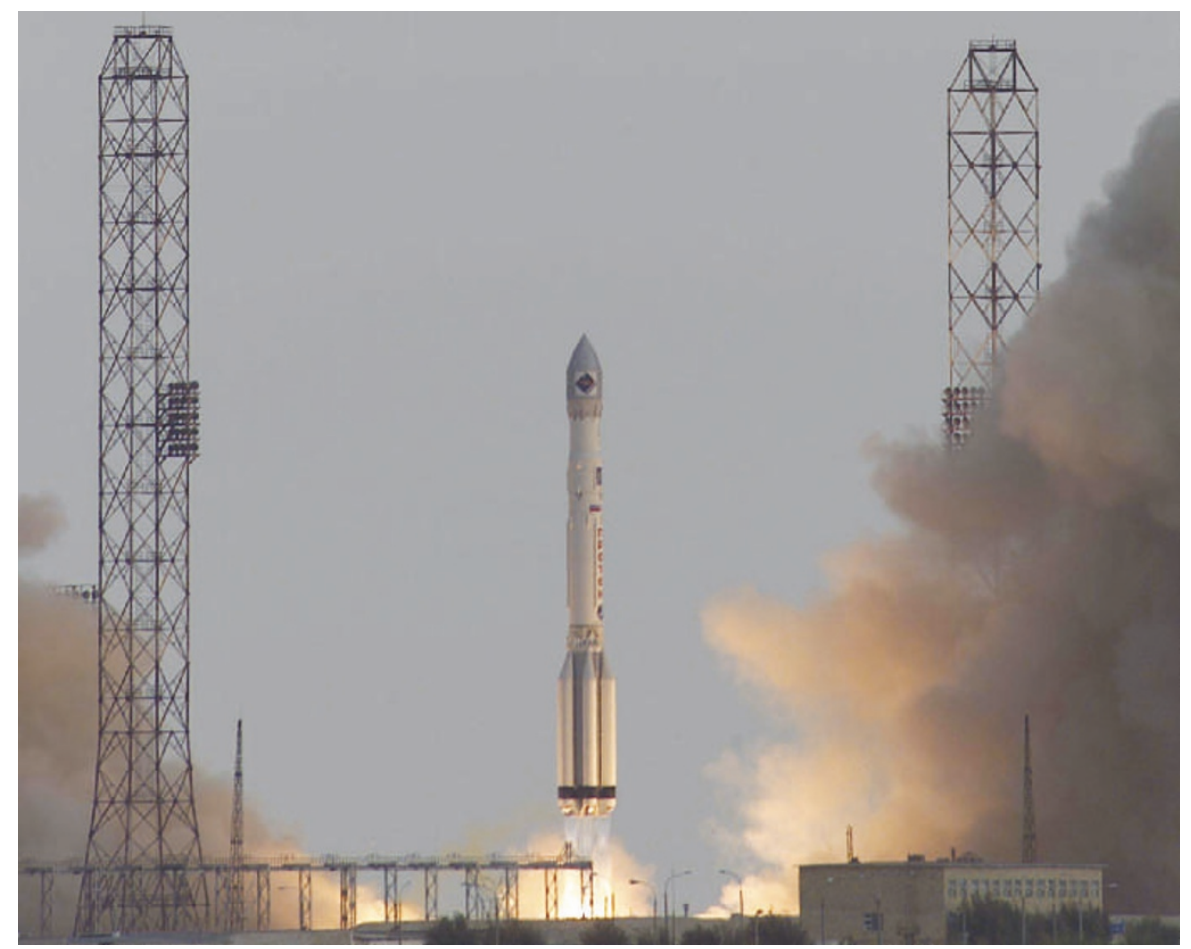

Unburned fuel from rockets launched at Baikonur could be causing ill health in Siberia.

But some question whether the Russian authorities will be willing to face up to any pollution. Baikonur is one of the world's busiest launch sites and a source of considerable income for the Russian government. One expert on the country's space industry, who asked not to be named, estimates that the profit on an individual commercial launch could be as much as US\$25 million.

Zykov says he has discussed the problem with Rosaviakosmos officials, but that they have a "negative attitude" to studies conducted outside their agency. And one scientist who has campaigned against the launches in the region alleges that he has been harassed by the FSB, the main successor to the Soviet KGB. Between 2000 and 2004, ecologist Sergey Pashenko of the Institute of Chemical Kinetics and Combustion in Novosibirsk studied pollution from a rocket testing ground in Biysk, also in the Altai. He says he was arrested twice and also had his equipment confiscated.

\section{Official view}

Rosaviakosmos rejected the conclusions of Zykov's study when approached by Nature. Spokesman Vyacheslav Davidenko says the agency monitors the health of local populations and has found no problem with the launches. The agency accepts that pollution occurs and says the regions involved are compensated, although it did not supply details of the sums involved. Davidenko adds that the affected areas contain so few people that the fuel has little human impact and any ill health is likely to be due to living standards in the Altai region, which are below average for Russia.

Others note that Russian researchers have previously been accused of producing alarming findings in order to attract funding from the West. Valerie Beral, an epidemiologist at Cancer Research UK in Oxford, points out that some studies of the 1986 Chernobyl nuclear disaster produced conclusions that could not be replicated. She says that the Baikonur issue deserves attention, but cautions that the same may be happening here.

The study does have the backing of the respected Moscow-based International Science and Technology Center. Zykov says that the centre and other funders provide about $\$ 11,000$ per month in funding for 35 researchers who have worked on the project.

Rosaviakosmos is considering alternatives to hydrazine, but has no immediate plans to replace the fuel. Proton launch vehicles, one of three types of Russian rockets that use hydrazine, are due to launch two telecommunications satellites from Baikonur this year.

Despite using Baikonur for launches, neither NASA nor ESA accepts responsibility for problems associated with the site. NASA says it is aware of the pollution, but notes that Rosaviakosmos has made "positive progress" in reducing the quantity of fuel released with spent rocket stages. An ESA spokesman said that the agency was only buying a service at Baikonur and was not responsible for the rockets. Most other major bases used by NASA and ESA, such as Cape Canaveral in Florida, send rockets out over the sea. 